Article

\title{
Social influences in recreational sport programs for emerging adults with a disability: A preliminary examination using a mixed methods approach
}

\author{
Krystn Orr ${ }^{1,2^{*}}$, Katherine A. Tamminen ${ }^{2}$, M. Blair Evans ${ }^{3}$, and Kelly P. Arbour- \\ Nicitopoulos ${ }^{1,2,4}$ \\ Received: 29 April 2020; Accepted: $25^{\text {th }}$ November 2020; Published: $21^{\text {st }}$ March 2021
}

\begin{abstract}
The purpose of this study was to examine the social experiences of emerging adults with disabilities within recreational sport programs. Focusing on the nature of social experiences during practice sessions as well as experiences transitioning into adult sport programs, the current research involved qualitative interviews and a group interview, along with researcher observations of athlete interactions during training sessions. A further goal was to develop an observational tool for coding social interactions within disability sport programs. Seven athletes from disability sport programs were observed and interviewed ( $28 \%$ female), with an intellectual impairment, as well as social, physical, or sensory impairments. Qualitative interviews and the group interview were thematically analyzed. A single training session in each program was recorded and coded using observational software, followed by analyses to describe the frequencies of social interactions and associations with athlete engagement. Observational findings demonstrated relatively greater interactions with coaches as opposed to teammates, with two athlete-cases illustrating associations between certain social interactions and engagement within the program. Interviews and the group interview provided insights into how social interactions influence athletes' transition into adult programs - with a focus on the salience of parents as well as a reflection on how peers and coaches have influenced their sport experiences. In addition to providing a lens for exploring sport transitions, this research involved the preliminary development of an observational tool for social experiences in disability sport programs that may be used in further research and practice.
\end{abstract}

Keywords: adolescents; social interactions; coaching; video observation

\section{Introduction}

Sport programs involve cohesive groups and social relationships among members and leaders, which can powerfully shape athletes' sport experiences (Erickson, Wright, Kochanek \& Vierimaa, 2020). Sport can be a social networking opportunity to ease the transition from adolescence to adulthood - a time period that Arnett (2000) refers to as emerging adulthood (ages 18 to 25 years). Ideal social environments might involve positive interpersonal relationships that promote program involvement, at the same time supporting well-being and personal development (Arnett, 2000). Social environments in sport settings may involve negative interactions that reduce motivation and harms program members 
(Eys, Bruner \& Martin, 2019). It is thus crucial to examine both the positive and negative influences of social interactions throughout athletes' trajectories within sport.

Peers are particularly salient within the social environment of sport programs (Evans, Eys \& Bruner, 2012), and are referred to as individuals who share similar characteristics to one another with or without pre-existing relationships (Loughead \& Hardy, 2005). In other words, peers may include any of the social influencers within the sport context that one engages within programs. Whereas, peers are traditionally considered to be athletes similaraged teammates, recent disability sport research casts a broader net around whom athletes consider to be their peers. Specifically, although coaches are not typically thought of as peers in sport psychology literature, recent literature on youth and emerging adults with a disability in sport, suggests that some athletes with a disability may characterize their coaches as peers (Orr, Tamminen, Sweet, Tomasone, \& Arbour-Nicitopoulos, 2018; Orr, Evans, Tamminen \& Arbour-Nicitopoulos, 2019). Thus, peers can adopt roles that influence the overall athlete experience of the program (Eys et al., 2019; Orr et al., 2018).

Athletes with disabilities often form fewer friendships with other individuals their own age, and often feel they are relative outsiders within the groups that form in their schools and communities (Pinquart \& Pfeiffer, 2015a, 2015b). Moreover, perceptions of belonging, such as, friendships, feelings of connection, and enabling engagement within the community otherwise known as social participation, are a fundamental human right (United Nations, 2006). As such, peers are important social influencers in establishing an environment where individuals perceive they belong (e.g., Evans et al., 2018; Renwick et al., 2019). Peers are particularly important to the sport experiences of athletes with a disability, advocating and recruiting for their sport (e.g., Wu \& Williams, 2001) and sharing experiential knowledge of life experiences (Solomon, 2004).

For athletes with a disability, peers may reduce perceived disablism (e.g., fostering an inclusive social environment; Richardson, Smith \& Papathomas, 2017), provide a level of credibility to the program (Chemtob et al., 2018) and, in parasport, aid in the recruitment of new team members (Wu \& Williams, 2001). Disablism involves discriminatory or oppressive actions directed toward individuals with disabilities. In the context of sport and recreation, this may be overt in some cases, but is often evident through the absence of efforts to adapt programming or staff members who are unwilling to learn the practices that may promote inclusion. Researchers have recognized the need for more robust research methods and perspectives that capture the complexity of peer interactions, relationships and groups in sport settings (Erickson et al., 2020; Murphy-Mills, Bruner, , Erickson, \& Côté, 2011; Rubin, Bukowski \& Parker, 2007), and few studies have addressed such complexities in athletes without a disability (e.g., Vierimaa \& Côté, 2016). To our knowledge, no research has addressed these complexities amongst peers with a disability in recreational sport programs, highlighting an important gap in the disability literature.

Peer interactions in disability sport may also entail negative experiences. Emerging adults with a disability may experience challenges navigating the social environment of sport programs, from harassment to poor psychosocial adjustment (Charalampos, Silva, \& Kudlacek, 2015; Young et al., 2009). If researchers and coaches hope to facilitate efforts to construct higher-quality disability sport experiences for emerging adults (Evans et al. ,2018), there must be a focus on assessing peer interactions and prioritizing strategies for fostering positive relationships with teammates and coaches in sport programs. The need to evaluate and shape the social environment is especially potent in recreational contexts where less research has been conducted compared to competitive sport settings (Oja et al., 2015). Hence, the current study examined the nature of social interactions in recreational sport for 
emerging adults with a disability, and perceptions of how these interactions shape transitions within sport.

\section{Observing Peer Interactions}

Existing literature on peer experiences have most commonly drawn from qualitative interviews as well as cross-sectional survey data. Whereas interviews in particular have the potential to derive richer understanding of how social interactions link to sport experiences (e.g., Bekker et al. 2020; Braun \& Clarke, 2019), behavioural observation is also a crucial approach to explore the complexity of interactions among peers (Murphy-Mills et al., 2011). Observational coding approaches are perhaps most widespread in sport studies examining coach-athlete interactions in youth and elite sport settings where the studies unpack the links between coach behaviours and athletes' subsequent responses during training sessions (Erickson, Côté, Hollenstein, \& Deakin, 2011; Turnnidge, Côté \& Hancock, 2014). In such behavioural observations, the observed setting is a dynamic system. Dynamic systems are complex sets of interactions that have "nonlinear interactions among system components, phases of sensitivity and insensitivity to outside influences, and rapid transitions between stable states" (Lewis, Lamey, \& Douglas, 1999, p. 457). Using a dynamic systems approach (Lewis et al. 1999), an evaluation of the sequence of behaviours that athletes enact in recreational sport settings can help to understand how athletes interact with each other and with coaches. For example, coaches can understand how behaviours are linked together to promote supportive environments (Keegan, Spray, Harwood, \& Lavallee, 2010), and longterm behavioural outcomes (Evans et al., 2018; Turnnidge, Côté, \& Hancock, 2014).

One aspect to consider through observation is communication style. Communication concerns the auditory and physical ways people transmit information to one another while building a personal rapport (Cobley, 2008). Yet, for some athletes with a disability, communication may pose a challenge due to impairment effects associated with their disability (Temple \& Walkley, 2007) and misinterpretation of communication (Marton, 2009). For example, Deaf athletes and some athletes with autism spectrum disorder use nonverbal communication styles (e.g., sign language). In sport settings, coaches have a unique social role for their athletes as a model of positive communication for athletes ( Turnnidge, Côté, \& Hancock, 2014). Therefore, use of mixed methods to explore the observations and connect with the athletes in a communication method of their choosing is important.

Moreover, engagement is an observable state and indicator of quality sport experiences (Evans et al., 2018). Engagement is multifaceted, including attention (e.g., whether the athlete is focusing on the task) and active participation (e.g., whether an athlete carries out an assigned task). In Turnnidge and colleagues (2014) observational study on parasport coaching, engagement was operationalized as active participation, focus, and maintained attendance. Given the impact coaches have on facilitating a quality social environment (Douglas, Falcão \& Bloom, 2018), coaches of athletes with a disability may benefit from information about patterns of social interactions and to construct positive environments with their athletes (Evans et al., 2018).

\section{Objectives and Research Questions}

To address the gaps in the disability and recreational sport literature, the current study used a mixed methods research design to explore the peer influences on emerging adult athletes with a disability in recreational sport program. The study addressed the following two research questions:

1. How do emerging adults with a disability in recreational sport programs interact within the social environment during practice sessions? 
2. What are the recreational sport experiences of emerging adults with a disability as they transition from youth to adult programs?

On one hand, it was crucial to observe and examine the role of 'acute' interactions with coaches and teammates as they unfurl within training sessions to gather a sense for the nature of these interactions. We therefore explored these questions by describing peer interactions that occur in recreational sport programs for emerging adult athletes with a disability through the frequency and duration of the interactions, and the sequencing of the athletes' interactions and (non)engagement in the activity. On the other hand, athlete insights are critical to understand the links between these types of social experiences in programming with broader transitions from youth programs and into adult programming. We therefore qualitatively explored the recreational sport experiences of emerging adult athletes with a disability from youth to adulthood, with an emphasis on the peer role on these experiences. By merging a focus on qualitative insights with behavioural observation, coding tool development was a supplemental goal of this research. We specifically sought to address the question: "Can observational coding be a feasible method for exploring behavioural interactions between peers in recreational sport programs with emerging adults with a disability?"

\section{Materials and Methods}

Adopting a critical realist perspective, the authors assumed a transcendental realist ontology and constructivist epistemology (Lincoln, Lynham, \& Guba, 2011; Smith, Sparkes, Phoenix, \& Kirkby, 2012). By taking this perspective, we acknowledge that reality is coconstructed between actors (e.g., researcher and participant) and we have a subjective understanding of the phenomenon explored. The authors are directly linked to the findings presented in this paper (i.e., our backgrounds influence the interpretations of the data). For example, the athletes share their experiences, the researchers understand what is being shared by the athletes, there is the reality of the events that is theoretically knowable, and the sports field and interview room is the space where it is all enacted. However, given our previous conceptualizations of the topic at hand, the assumptions we as researchers make are disconnected from the athletes' experiences and the reality of the events. The authors identify as White, privileged individuals with research and teaching experience in exercise and sport psychology, adapted physical activity, group dynamics, and parent-coach-athlete interactions. None of the authors identify with a disability. Two authors have children, one of these children identifies with an invisible disability. Three of the authors have coaching experience in dance, Special Olympics, and athletics. All authors participated in sport.

\section{Design}

This study followed a triangulation mixed methods design, which uses multiple methods in a dialectical process to gain a deeper, nuanced understanding of the research topic (Creswell \& Plano Clark, 2020; Lincoln and Guba 1985; McKim 2017; Mertens and HesseBiber 2012). A video observation of recreational sport programs, taken by the first author, was used to code the interpersonal interactions occurring within the athletes' respective programs. Interviews explored (a) athletes' transition to adult sport (e.g., how long have you been in sports? Tell me about that; circulate and allow conversations in group interview), (b) experiences with recreational sport (e.g., how do sports make you feel?), (c) the people that influenced their participation (e.g., who do you do sports with?), and (d) who are your peers in sport and elsewhere. The institutional research ethics board granted approval for this study. 


\section{Recruitment}

Using purposeful-maximum variation sampling, eligible athletes were recruited from organizations across Ontario, Canada that provide recreational sports for emerging adults (age 18 to 25 years) with a disability. Namely, programs from across the province of Ontario were contacted by the first author via email to capture urban and rural regions, then athletes were purposefully selected based on a set of eligibility criteria and to acquire a diverse sample. Eligible athletes were 18 to 25 years old, able to understand and communicate in English, and were currently participating in recreation sport(s). Electronic advertisements were sent to athletes and their families by a contact (coach or parent) at the program. Word of mouth was also used. Athletes scheduled the observation and interview with the first author. The first author informed the coach of the study and observation date. Athletes provided written consent on the first meeting with the first author, then verbally reconsented on subsequent meetings.

\section{Athletes}

Athletes were two women and six men aged 18 to 25 years $(M=22.38 \pm 3.62$ years $)$. Seven athletes were observed in three recreational sport programs: curling $(n=1)$, basketball $(n=1)$, and softball program $(n=5)$. For the swimmer, no video observation was conducted given the challenges with videotaping in a drop-in facility, however two interviews occurred over one month to discuss the swimmer's experiences at the pool that month. Athletes lived in urban $(n=1)$, rural $(n=1)$, and suburban $(n=5)$ regions in Ontario. Athletes self-identified as having a diagnosis of autism spectrum disorder $(n=1)$, cerebral palsy $(n=1)$, hearing impairment ( $n=1)$, visual impairment $(n=1)$ or mild intellectual disability $(n=5)$. All observed athletes engaged in their sport programs independently and without mobility aids. Athletes were interviewed individually $(n=5)$ or with a parent present $(n=3)$. Parental presence was at the request of the athlete. Parents were asked to observe only; however, some parents did answer and support their adult child's responses to interviewer questions. The authors acknowledge the added complexity to the power dynamics within a parent-attended interview versus an athlete-only interview (Gardner \& Randall, 2012). For example, the interviewer had to ensure the athletes' voices were prioritized over their parents such that the parents could support communication but not be the central focus.

\section{Recreational Sport Programs}

All three observed sport programs were designed for individuals with intellectual disabilities. Program sessions were 60 to 90 minutes with weekly training sessions and occasional games scheduled outside of this practice time. The programs had head coaches with multiple assistant coaches and volunteers. Program sizes ranged from 10 to 30 athletes, with an athlete-to-staff ratio ranging from 3:1 to 5:1. Cumulatively, coaches were five women and nine men. One program's coaches came from a local university and the other two programs' coaches were family of current or former team athletes.

\section{Procedure}

Athletes completed a brief demographic survey to collect data on age, gender, and disability type. Interviews were audio recorded and transcribed verbatim by the first author within 48 hours of the interview. The first author kept field notes throughout data collection providing setting details (e.g., a sketch of the layout), initial interpretations of the interview and observation, and context for analysis. All participants were assigned pseudonyms for anonymity.

Based on the athletes' availability, the observation occurred concurrently or within a week of the interview. The first author arrived approximately 20 minutes early to setup the video observation equipment (described below) and to inform the team about the recording. 
This step was required as individuals other than the participant-athlete were captured in the videos (Turnnidge, Côté, Hollenstein, \& Deakin, 2014).

\section{Data Collection and Analysis}

\section{Video Observations}

Video observations were made using Noldus Media Recorder $₫$ software. The camera was placed to capture the entire field of play (e.g., dugout) and was deemed safe by the coach. Following the procedures of Erickson et al. (2011) and Turnnidge, Côté, Hollenstein, \& Deakin, (2014), only the target athlete provided consent. The entirety of the sport program session was recorded.

\section{Observational Coding System}

This study modified a validated coach-athlete observational coding system (e.g., Allan Turnnidge, Vierimaa, Davis, \& Côté, 2016; Turnnidge, Côté, Hollenstein, \& Deakin, 2014) to include teammate interactions. The original behavioural observational coding system consisted of eight codes and used a dynamic systems approach (Erickson et al., 2011; Turnnidge, Côté, Hollenstein, \& Deakin, 2014). Athletes' immediate responses to interactions is a dynamic system focusing on the changes that occur within the phenomena (Lewis et al., 1999). Specifically, the observed athlete may react in a predictable way to behaviours of those around them indicating an 'attractor' that is a temporarily stable state (Lewis et al., 1999). Attractors over time may lend themselves to being states of behaviour that are most likely to occur in a given situation. For example, if an athlete can be off-task for an extended period of time without a coach or teammate engaging with them, this may become an 'attractive' state with the athlete not fully participating in the program.

The codes in the modified observational coding system are divided into two distinct categories that were used to simultaneously code the videos: engagement (i.e., engaged or not engaged) and communication strategies (e.g., activity feedback and negative verbal interaction). Engagement categories are defined by the athlete's attention and physical participation in the activities (e.g., a coach models a skill and the athlete watches - coded as 'engaged'). The communication strategies categories are defined by the verbal and nonverbal communication that occurs between athletes, teammates, and coaches. These communication strategies are based on coaching strategies (e.g., modeling). Additional codes were added to reflect the potential for negative peer interactions. Within the peer and disability sport literature, negative peer interactions (i.e., verbal, social/nonverbal, and physical bullying-type behaviours) have been reported among youth and emerging adults in a variety of settings including sport and school (Orr et al., 2018; Orr, Evans, et al., 2019). Three additional codes, verbal, social, and physical negative behaviours, were added to the coding scheme under the communication strategy category for a total of 11 distinct codes. See Table 1 for definitions and examples of each code. The authors, a developer of the original coding system and an expert in adapted sports reviewed the modified observational coding system and the codes were applied to observing a physical literacy program for children with a disability to ensure that the added behaviours were observable and unique. For behaviours not captured on camera or that were undeterminable, a code of 'other' was used. The division of codes into categories is a modification to the original coding system.

The first author used Noldus Observer XT® software to code and analyze the observational data. The state space grid methodology (Lewis et al., 1999) quantified athletes' engagement in response to the communication strategies. The first author coded continuously for behaviours lasting at least three seconds with engagement and communication strategy codes (Table 1) coded simultaneously (Turnnidge, Côté, Hollenstein, \& Deakin, 2014). Behaviours were analyzed using descriptive (i.e., type, 
frequency, and duration) and lag sequential analyses (i.e., temporal sequence). No negative behavioural interactions occurred and were removed from further analyses. For the lag sequential analysis, only the curling and basketball athletes' observed sports were used given that the softball video included five observed athletes across a large field, making detailed coding difficult and unusable for this portion of the analysis (e.g., content of discussions unidentifiable).

Table 1. A summary of the modified observational coding system.

\begin{tabular}{lll}
\hline Code & Definition & \multicolumn{1}{c}{ Example from Study } \\
\hline Engaged & \multicolumn{1}{c}{ Engagement Behaviours } \\
& $\begin{array}{l}\text { The athlete* is participating in the } \\
\text { assigned activity, based on } \\
\text { instructions from the coach. }\end{array}$ & $\begin{array}{l}\text { Athlete shooting baskets once } \\
\text { basketball coach asks the team to } \\
\text { do so. }\end{array}$ \\
\hline Not Engaged & $\begin{array}{l}\text { The athlete loses focus, initiates } \\
\text { unassociated activities, removes } \\
\text { themselves from the activity, or } \\
\text { exhibits self-harm behaviours. }\end{array}$ & $\begin{array}{l}\text { Athlete walks away from the } \\
\text { team's curling sheet and looks } \\
\text { toward ceiling. }\end{array}$ \\
& & \\
\hline
\end{tabular}

\section{Communication Strategies}

\begin{tabular}{|c|c|c|}
\hline Modelling $^{+}$ & $\begin{array}{l}\text { A physical demonstration is } \\
\text { provided of a sport-specific or } \\
\text { social skill by a coach, teammate, } \\
\text { or the athlete. }\end{array}$ & $\begin{array}{l}\text { The curling coach directs the } \\
\text { team's attention to a teammate's } \\
\text { throw. }\end{array}$ \\
\hline Activity Feedback ${ }^{+}$ & $\begin{array}{l}\text { Constructive feedback is provided } \\
\text { immediately following the } \\
\text { performance of a sport-related skill. } \\
\text { Can be initiated by a coach, } \\
\text { teammate, or the athlete. }\end{array}$ & $\begin{array}{l}\text { A coach makes a recommendation } \\
\text { for hand placement when swinging } \\
\text { the baseball bat. }\end{array}$ \\
\hline $\begin{array}{l}\text { Activity } \\
\text { Communication }^{+}\end{array}$ & $\begin{array}{l}\text { The coach directs the team or } \\
\text { athlete for the next sport-related } \\
\text { activity. Can be initiated by a } \\
\text { coach, teammate, or the athlete. }\end{array}$ & $\begin{array}{l}\text { The coach gathers the team to } \\
\text { describe the session's schedule } \\
\text { and divides team into working } \\
\text { groups. }\end{array}$ \\
\hline General Feedback $^{+}$ & $\begin{array}{l}\text { Immediate feedback following the } \\
\text { performance of a sport-related skill } \\
\text { that is non-specific. Can be initiated } \\
\text { by a coach, teammate, or the } \\
\text { athlete. }\end{array}$ & $\begin{array}{l}\text { The athlete says "good job" or } \\
\text { "nice" to fellow teammate } \\
\text { following a successful basket. }\end{array}$ \\
\hline $\begin{array}{l}\text { General } \\
\text { Communication }^{+}\end{array}$ & $\begin{array}{l}\text { The athlete, teammates, or coach } \\
\text { have a conversation that is not task } \\
\text { specific. }\end{array}$ & $\begin{array}{l}\text { The athlete and a teammate chat } \\
\text { about their weeks at the end of the } \\
\text { curling rink while waiting their } \\
\text { turn to shoot. }\end{array}$ \\
\hline Other & $\begin{array}{l}\text { Any behaviours that are not } \\
\text { captured on camera or undefinable } \\
\text { by the observer(s). }\end{array}$ & $\begin{array}{l}\text { The athlete walks out of frame of } \\
\text { the camera. } \\
\text { The athlete is too far away to } \\
\text { discern the content of their } \\
\text { conversation with a teammate. }\end{array}$ \\
\hline Negative Verbal $^{++}$ & $\begin{array}{l}\text { The athlete or teammate/coach says } \\
\text { something that elicits a negative } \\
\text { emotional reaction from the target } \\
\text { of the comment. }\end{array}$ & Not observed in current study. \\
\hline Negative Social $^{++}$ & $\begin{array}{l}\text { Exclusionary behaviours from } \\
\text { athlete or teammates towards an } \\
\text { individual or group. }\end{array}$ & Not observed in current study. \\
\hline Negative Physical $^{++}$ & $\begin{array}{l}\text { Aggressive physical action that may } \\
\text { or may not lead to physical injury. }\end{array}$ & Not observed in current study. \\
\hline
\end{tabular}

Note. *athlete is used throughout to indicate the target individual being observed; +indicates positive behaviour; ++added codes. 


\section{Inter- and Intra-Observer Reliability}

A second coder was trained on the coding scheme by the first author to assess the interobserver reliability. The second coder worked with the first author to learn the Noldus Observer XT® software. The second coder coded 7 minutes of the softball program for two athletes (a total of 14 minutes). These two athletes were selected as the most difficult to follow in the video: identical twins and often far from the camera. Inter- and intra-observer reliability were calculated with matching codes occurring within 5 -seconds of each other. Both inter- $(k=0.92)$ and intra-observer $(k=0.89)$ reliabilities were deemed as acceptable (Erickson et al., 2011; Turnnidge, Côté, Hollenstein, \& Deakin, 2014).

\section{Interviews and Group Interview}

Individual interviews $(n=3)$ and one group interview were conducted with five athletes (from the same team). The interviews and group interview were held at either the sport training facility or at a public café and lasted from 15 to 65 minutes ( $M=28.4$ minutes, $S D=21.5$ ). A group interview was conducted because the five softball athletes had limited time to participate in the study and were in a remote location. Therefore, a group interview was conducted with all the athletes.

As previously noted, three athletes desired a parent (or both) to be present during their interview. Parents were asked to silently observe. However, parents did support their adult children in these interviews to varying degrees. For example, some athletes could not remember some details of their experience and asked their parent(s) for assistance. Another athlete relied on their parent to rephrase the interview questions or to probe for a memory that the parent thought was relevant. In either case, the parents' statements were transcribed verbatim and analyzed in the context of the larger conversation.

The first author conducted a reflexive thematic analysis (Braun \& Clarke, 2019), such that themes have shared meaning that are philosophically and theoretically informed. The process is iterative, with critical reflection occurring throughout the analysis, and collaborative "to develop a richer more nuanced reading of the data" (Braun \& Clarke, 2019, p. 594) with the co-authors acting as critical friends. Braun and colleague's (2016) six steps were followed: Familiarization - the re-reading and listening to the audio-recordings by the first author, coding - the first author inductively analyzed the transcripts highlighting and drafting names for the meaning units identified, theme development - grouping related codes the first author developed preliminary themes, theme refinement - in collaboration with the co-authors, the first author discussed the initial themes and codes as they related to theory and practice, refining for clarity, and theme naming and writing up were completed together as the writing process further clarified the themes and, thus, theme names were derived by the authors.

\section{Rigour}

The authors used O'Cathain's (2010) framework to assess and ensure study rigour under eight domains: planning quality; design quality; data quality; reporting quality; interpretive rigour; inference transferability; synthesizability; and, utility. Throughout the O'Cathain's (2010) framework, transparency is essential which is why the authors have detailed their personal, philosophical, and methodological assumptions and decision-making processes. Ensuring interpretive rigour, the findings are clearly identified as data from the quantitative or qualitative phases of the study. Where conflicts arose between the data, findings are presented equally and critically reflected upon. The authors aimed to provide practical, theoretical, and methodological implications, enhancing the study's inference transferability and utility. 


\section{Results}

The findings are organized into three sections. The first section, Behavioural Observations, presents behavioural descriptions of the observational coding data. The second section, Being Social in Recreational Sport Programs, is a qualitative exploration of the interviews with athletes exploring their experiences in and transitions into adult sport programs in two sub-themes: Parents at Play and Where are the Peers. These themes aim to 'show' the readers our analysis and the discussion will 'tell' the reader how it relates (or not) to the extant literature. The third section, Sequencing Peer Communication with Program Engagement, integrates the qualitative (interview) data with the observed sequence of athlete behaviours.

\section{Behavioural Observations}

In this section, a descriptive description of the observational coding data is presented. A total of 545 behaviours (Table 2) and 315.9 minutes of observed time (Table 3) are included in the analyzed data.

Table 2. Frequency of behaviours by athlete

\begin{tabular}{|c|c|c|c|c|c|c|c|c|c|c|c|c|}
\hline \multirow{2}{*}{\multicolumn{2}{|c|}{ Athlete }} & \multirow[b]{2}{*}{ Gender } & \multirow[b]{2}{*}{ Total } & \multicolumn{3}{|c|}{ Engagement Behaviour } & \multicolumn{5}{|c|}{ Communication Behaviours } & \multirow[b]{2}{*}{ Total } \\
\hline & & & & $E$ & $O$ & Total & $A C$ & $A F$ & $G C$ & $G F$ & $M$ & \\
\hline \multicolumn{2}{|l|}{ Curling } & Male & 273 & 49 & 16 & 107 & 68 & 13 & 49 & 16 & 20 & 166 \\
\hline \multicolumn{2}{|c|}{ Basketball } & Male & 152 & 16 & 0 & 30 & 48 & 20 & 32 & 20 & 2 & 122 \\
\hline \multicolumn{2}{|c|}{ Softball } & Male & 30 & 8 & 4 & 18 & 2 & 0 & 10 & 0 & 0 & 12 \\
\hline \multicolumn{2}{|c|}{ Softball } & Male & 25 & 6 & 2 & 10 & 8 & 0 & 7 & 0 & 0 & 15 \\
\hline \multicolumn{2}{|c|}{ Softball } & Male & 33 & 8 & 6 & 16 & 4 & 2 & 11 & 0 & 0 & 17 \\
\hline \multicolumn{2}{|c|}{ Softball } & Female & 14 & 4 & 4 & 8 & 2 & 0 & 4 & 0 & 0 & 6 \\
\hline \multicolumn{2}{|c|}{ Softball } & Female & 18 & 4 & 4 & 8 & 2 & 0 & 8 & 0 & 0 & 10 \\
\hline & & Total & 545 & 95 & 6 & 197 & 134 & 35 & 121 & 36 & 22 & 348 \\
\hline \multicolumn{13}{|c|}{$\begin{array}{l}\mathrm{E}=\text { Engaged; } \mathrm{NE}=\text { Not Engaged; } \mathrm{O}=\text { Other; } \mathrm{AC}=\text { Activity Com } \\
\text { General Communication; } \mathrm{GF}=\text { General Feedback; } \mathrm{M}=\text { Modeling }\end{array}$} \\
\hline \multicolumn{13}{|c|}{ Table 3. Behaviour durations in seconds by athlete } \\
\hline \multirow{2}{*}{\multicolumn{2}{|c|}{$\begin{array}{l}\text { Athlete } \\
\text { Gender }\end{array}$}} & Total & \multicolumn{4}{|c|}{ Engagement Behaviour } & \multicolumn{6}{|c|}{ Communication Behaviours } \\
\hline & & Time & $\mathrm{E}$ & $\mathrm{N}$ & $\mathrm{O}$ & Total & $\mathrm{AC}$ & $\mathrm{AF}$ & GC & GF & $\mathrm{M}$ & Total \\
\hline Curling & Sum & 7227.3 & 4272.5 & 423.1 & 1146.5 & 5842.1 & 763.3 & 45.6 & 384.0 & 58.0 & 134.4 & 1385.3 \\
\hline \multirow{2}{*}{ Male } & Mean & 26.5 & 87.2 & 10.1 & 80.9 & & 11.2 & 3.5 & 7.8 & 3.6 & 6.7 & \\
\hline & SD & 91.0 & 157.3 & 17.6 & 236.9 & & 16.9 & 4.5 & 14.8 & 4.7 & 10.0 & \\
\hline Bball & Sum & 4635.5 & 3065.6 & 96.5 & 0.0 & 3162.1 & 924.0 & 83.9 & 225.5 & 131.7 & 108.4 & 1473.4 \\
\hline \multirow{2}{*}{ Male } & Mean & 30.5 & 191.6 & 6.9 & & & 19.3 & 4.2 & 7.1 & 6.6 & 54.2 & \\
\hline & SD & 131.6 & 368.5 & 11.2 & & & 43.2 & 5.7 & 14.9 & 12.2 & 76.7 & \\
\hline Softball & Sum & 3381.3 & 1915.0 & 24.6 & 50.1 & 1989.7 & 1351.1 & $\mathbf{0 . 0}$ & 40.5 & $\mathbf{0 . 0}$ & $\mathbf{0 . 0}$ & 1391.6 \\
\hline \multirow[t]{2}{*}{ Male } & Mean & 112.7 & 239.4 & 4.1 & 12.5 & & 675.5 & & 4.1 & & & \\
\hline & SD & 363.1 & 523.5 & 7.8 & 21.6 & & 955.3 & & 5.2 & & & \\
\hline Softball & Sum & 2721.7 & 1890.9 & 6.4 & 92.4 & 1989.7 & 636.3 & 0.0 & 95.7 & 0.0 & 0.0 & 732.0 \\
\hline \multirow[t]{2}{*}{ Male } & Mean & 108.9 & 315.2 & 3.2 & 46.2 & & 79.5 & & 13.7 & & & \\
\hline & SD & 318.06 & 597.4 & 4.5 & 65.36 & & 200.35 & & 19.71 & & & \\
\hline Softball & Sum & 2140.5 & 1865.0 & 3.1 & 121.6 & 1989.7 & 60.2 & 12.4 & 78.2 & 0.0 & 0.0 & 150.8 \\
\hline \multirow[t]{2}{*}{ Male } & Mean & 64.9 & 233.1 & 1.6 & 20.3 & & 15.1 & 6.2 & 7.1 & & & \\
\hline & SD & 235.1 & 456.8 & 2.2 & 30.3 & & 21.2 & 8.7 & 10.5 & & & \\
\hline Softball & Sum & 2052.9 & 1513.8 & 0.0 & 475.9 & 1989.7 & 45.0 & 0.0 & 18.3 & 0.0 & 0.0 & 60.2 \\
\hline \multirow[t]{2}{*}{ Female } & Mean & 146.6 & 378.5 & & 119.0 & & 22.5 & & 4.6 & & & \\
\hline & SD & 386.9 & 696.1 & & 232.1 & & 31.8 & & 5.5 & & & \\
\hline Softball & Sum & 2136.4 & 1907.6 & 0.0 & 81.5 & 1989.7 & 45.0 & 0.0 & 102.4 & 0.0 & 0.0 & 147.3 \\
\hline \multirow[t]{2}{*}{ Female } & Mean & 118.7 & 476.9 & & 20.4 & & 22.5 & & 12.8 & & & \\
\hline & SD & 361.5 & 720.1 & & 26.5 & & 31.8 & & 21.3 & & & \\
\hline
\end{tabular}


Overall, athletes were engaged $56.9 \%$ of the time in coach-assigned tasks (e.g., batting in softball). Athlete engagement was preceded by athlete- $(84.1 \%)$, coach- $(8.7 \%)$ and teammate- $(7.3 \%)$ initiated behaviours. For the remaining observations, athletes were either not engaged (39.5\%) or coded as 'other' (21.6\%). The 'other' behaviours were primarily when athletes were not distinguishable in the video.

The communication strategies, observed in descending order, include activity communication (38.5\%), general communication (34.8\%), general feedback (10.3\%), activity feedback (10.1\%), and modelling (6.3\%). Communication behaviours were initiated by coaches (60.7\%), the athlete (24.6\%), and teammates (14.8\%).

\section{Being Social in Recreational Sport Programs}

\section{Parents at Play}

This theme describes the athletes' search for belonging and meaning in sport contexts with the influence of parents ever-present. Although each athlete experienced their transition from youth to adult sport programs differently, one commonality was the limited influence of peers and the ever-present influence of parents. Parents had an active role in the athletes' sport experiences that became the primary discussion point of the interviews.

Parents enrolled and drove athletes to their sport programs with some parents even coaching the athletes as Chase's (basketball) quote depicts.

Interviewer: Do you have a para-athletics team up here [northern Ontario] to train with?

Chase's Mother: It's just him and dad. There's no track clubs up here that do [provincial sport organization], so he has to train as an independent athlete.

Chase: Weight training I'm on my own, well with my dad. I mean without other athletes.

For Chase, recreational sport programs supplemented his drive for being a national team athlete. Contrastingly, the other athletes interviewed spoke of their use of sport to stay fit, engage in their communities, and enjoyed meeting other people; all of which was supported by a parent or guardian. For example, Hadi discussed his swimming and strengthbased fitness routine as being dependent on a family member:

What happens is that when we do the weights, my guardian or whoever I'm with, whether it's my father or my brother, shows me which weights are which and they show me how to set the weights and I just lift them.

Meanwhile for Ron, softball was a social outlet that his parents' softball team supported and played against. As well, Ron's colleagues supported his sport team:

It's always fun to play with different people. We always do something new. We just played, umm, [co-worker's] team at work over there that came over as a team to play against us.

Not all sport programs provided a positive social experience for the interviewed athletes. Finding a team with other athletes with whom they could connect was important for the athletes' participation. Parents were actively involved in identifying and enrolling all the athletes into their sports programs, even during emerging adulthood. For sisters, Lizzie and Suzie (softball), their mother initially enrolled them in women's league softball where felt that they did not fit in (as noted below by Suzie) and their mother presented an alternative team for them to try. This was demonstrated when Suzie described not being able to socialize and communicate with her teammates: 
We, Lizzie and I, used to do a girls' softball league, but we couldn't really interact with them. They talked about stuff we don't understand, and they don't really talk to us. Then mom suggested that we try [name of organization] softball. That's when we started coming here. She said that she wasn't sure we'd like it because we're not like some of these people [teammates]. But we can talk to them better. They talk about the same things I like to talk about.

For Suzie and Lizzie, their mom initially did not want the stigma associated with the term disability. This interpretation is made by the way Suzie describes her teammates as "these people" - at which time she gestured towards her team (taken from interviewer's field notes). However, Suzie and Lizzie did not want to return to the local adult softball league and their mom presented them with an alternative - a disability softball team that includes athletes of similar abilities regardless of disability diagnosis (field notes).

Comparatively, Hadi struggled to find a sport program once he graduated high school and had aged out of youth sport programming. He was newly enrolled in university and his priority was obtaining access to learning materials and navigating the campus. At the time of the interviews, Hadi attended a private fitness centre where he continued swimming and his fitness regime with the support of his family - primarily his brother or father. While this routine kept him active, he sought to belong independently in the space (fitness centre and pool) and his student community (university).

Interviewer: So, when you were talking about the pool and almost having to 'fight' for your lane space, how does that make you feel?

Hadi: It makes me feel - well I try, but it makes me feel kind of disappointed. Like say if a lane is busy one day then I can't swim and I love to swim and do laps, like lengths back and forth. So, it kind of disappoints you sometimes when the pool is busy.

Interviewer: And if the pool is busy, you said you go to the sauna?

Hadi: Yeah.

Interviewer: What else is available if the pool is busy?

Hadi: Well, the hot tub is also available. They have like a spa...So, I might sit in the hot tub and have a talk - just talk to my brother or whoever is with me for a bit.

As Hadi explains, the fitness centre and pool he attends is filled with people, yet he does not have an opportunity to connect with them, rather his parents or brother provide his sole source of social interaction in this physical space. We interpret presence as the first step in peer interaction. Without being able to be present in the same spaces as peers in a safe and inclusive manner, peer interactions cannot occur.

\section{Where are the Peers?}

Regardless of who they spoke of as peers (i.e., coaches, teammates, non-sport relations), the athletes found it challenging to describe how their peers supported or contributed to their sport experiences. To them it was simple, "It's an awesome sport. It works and the team works" (Kevin, softball). Some athletes noted that they liked to "talk with them [teammates]. Even when we're in the box [dugout], we talk a bit" (Ron, softball). Regardless of who their peers were, the athletes wanted "my friends who I know" (Jon, softball) to be part of their sport programs.

Throughout the interviews and following the observational coding, it became clear to the authors that peers as teammates were not spoken of or interacted with often. That is not to say that peers had no influence on the athletes' sport participation; rather, peers' presence was almost taken for granted. For example, the athletes all described being on their teams 
in their disability sport leagues for many years with many of the same teammates from youth to adulthood, and they imagined their future sport would occur the same way. However, Hadi (swimming) did reflect on who his peers were and why he considered them his peers:

Well, I have many peers. One of my peers was the staff at [school]. There was this one teacher named Mr. A and I went to this sports camp with him. Because he knew how strong I was, I developed the nickname The Beast. And I also have another peer, and that was in my high school, named Mrs. B... because I'm blind, visually impaired, she learned Braille and she's now learning how to teach students who are blind. So, I inspired her.

As Hadi described, while not being conventional age-matched peers, the teachers and coaches he identified as peers made him feel like he belonged in sport, they supported his skill development (sport and academic), and there was reciprocal learning between himself and his peers. Neither Hadi nor the other athletes described other peers in their recreational sport settings having any specific influence on their sport participation.

\section{Sequencing Peer Communication with Program Engagement}

To provide a more in-depth illustration of the social interactions occurring during the sport program practices, two cases of behavioural interactions are presented of the curling (Adam) and basketball (Chase) athletes. These cases integrate the qualitative and quantitative data such that observations may be better understood from the athletes' own voices.

\section{Autism on the Curling Sheet}

The curling program was attended by adults (ages 18 to 64) with intellectual disabilities with the observed athlete (Adam) being the youngest. There was one coach with three assistant coaches on the ice for 10 athletes. Parents watched the program from a viewing area, located behind a window and were unable to interact with the athletes for the duration of the program.

Adam's engaged behaviour, shown in Figure 1, occurred following his coach providing activity feedback (once) and general communication with a teammate (once). For example, Adam and a teammate were waiting their turn to throw the stone and spoke to each other, then returned to watching the curling game. This was Adam's only occurrence of a social interaction with a peer. Otherwise, Adam stood on his own or engaged with the activity at hand. Adam's limited peer interactions are described in the following interaction:

Interviewer: Do you go on your own to practice skating or with a coach?

Adam: No. I go on my own.

Interviewer: That's good. Do you like to go with anyone?

Adam: [points towards his father]

Interviewer: Do you play with the other people or do you stay on your own?

Adam: I usually participate with the rest.

Adam's Father: Yeah, he's in it.

Interviewer: Do you have friends that go to programs with you?

Adam: No.

Adam's Father: He has people he gets along with.

Adam: Yeah. 


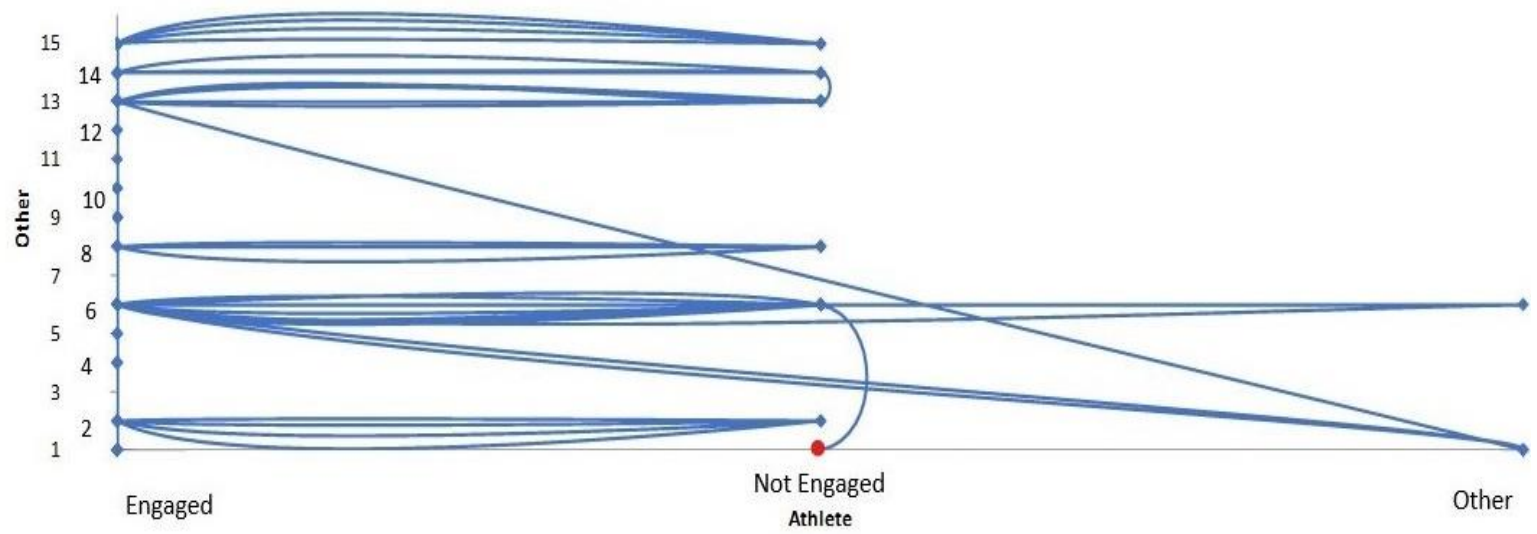

Figure 1. Behavioural sequence of the male curling athlete comparing engagement and communication behaviours. 'Other' behaviours indicate when the video was not otherwise coded such as walking off screen. The circle indicates the commencement of behavioural sequence. Note. 1 - Other (Athlete); 2 - Modeling (Peer); 3 - Modeling (Coach); 4 - Activity Communication (Athlete); 5 Activity Communication (Peer); 6 - Activity Communication (Coach); 7 - Activity Feedback (Athlete); 8 - Activity Feedback (Peer); 9 - Activity Feedback (Coach); 10 - General Feedback (Athlete); 11 General Feedback (Peer); 12 - General Feedback (Coach); 13 - General Communication (Athlete); 14 - General Communication (Peer); 15 - General Communication (Coach)

Adam's non-engaged behaviour often followed activity communication from the coach to the team (six times). For example, the coach spoke to the team and Adam would pace or look up at the ceiling. The coach approached Adam to regain attention by saying his name or left him to return to the activity on his own. More transitions between engaged and nonengaged behaviours occurred in the latter portion of the session. During these occurrences, Adam often displayed stereotypies, seen among individuals with autism spectrum disorder (e.g., pacing).

Additionally, Adam's stereotypy and topic fixation occurred throughout the interview. While the content was irrelevant to the focus of this study, it displayed his passion for the topic. The same passion was not displayed when speaking about his recreational sport experiences. For example, Adam loved to walk around shopping malls and examine stores (e.g., layout):

Adam: Did you know there used to be another [store name] in [the city]? ...

Interviewer: At the central mall?

Adam: [shakes his head]

Interviewer: The east mall?

Adam: Yeah! That one's gone too! Are they building anything in the old [store] now?

Comparatively, Adam never initiated a conversation around his sports and responded in monotone, quick answers. In these cases, his father stepped in to expand on Adam's point.

Adam's Father: What did you do two weeks ago?

Adam: I went to play soccer outside.

Adam's Father: Yeah, he played outside in a kind of pick-up game. There is artificial turf, and the guys were very friendly to him. They called him in to join them.

While not enthusiastic about discussing this impromptu soccer scrimmage, the discussion of his experience highlights Adam's willingness to interact with peers in unstructured as well as structured sport settings. 


\section{Shooting Hoops to Crosstrain}

The basketball program Chase participated in served a large rural area and was aimed at faster paced play for adults with intellectual disability (as Chase described, "I'm in the faster kind of group"). While Chase did not have an intellectual disability (self-identified as having cerebral palsy), the program accepted a wide range of athletes given the lack of sport opportunities available to emerging adults with a disability in the region. Parents and the first author sat in the entranceway to the gymnasium to observe the program session.

Chase's engaged and non-engaged behaviour most often occurred following general communication strategies initiated by him (Figure 2). For example, Chase walked over to the sidelines to get his water bottle and spoke with his parents or the head coach briefly. Chase was never told by a coach that his behaviour walking away from the activity distracted from the task or others. Otherwise, Chase did not have conversations with his peers or coaches. He remained focused on the assigned tasks but did not interact in a socializing way other than with his parents.

Interviewer: Do you know any of the people in the basketball program?

Chase: No.

Chase's Mom: Well in the first group there is. Yeah, a friend from school is there.

Chase: She's in the kind of lower kind of group, slower. I'm in the faster kind of group.

Interviewer: So, you don't really know anybody in your group outside of here?

Chase: I know them here, but I don't really know them outside of here.

Sometimes here and there I'll see them at different sports and stuff or at school.

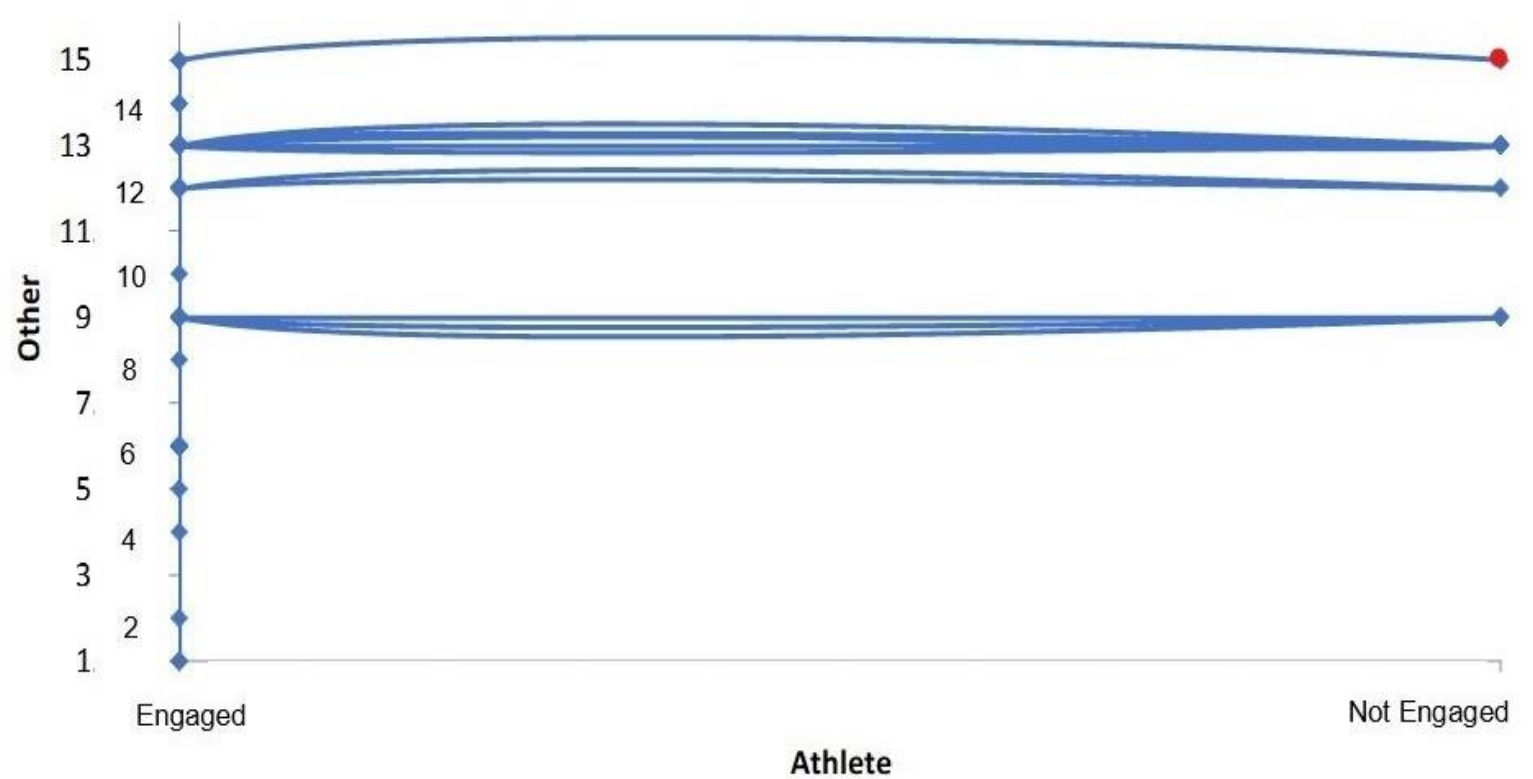

Figure 2. Behavioural sequence of the male basketball athlete comparing engagement and communication behaviours. The circle indicates the commencement of behavioural sequence. Note. 1 - Other (Athlete); 2 - Modeling (Peer); 3 - Modeling (Coach); 4 - Activity Communication (Athlete); 5 - Activity Communication (Peer); 6 - Activity Communication (Coach); 7 - Activity Feedback (Athlete); 8 - Activity Feedback (Peer); 9 - Activity Feedback (Coach); 10 - General Feedback (Athlete); 11 - General Feedback (Peer); 12 - General Feedback (Coach); 13 - General Communication (Athlete); 14 - General Communication (Peer); 15 - General Communication (Coach) 
Chase also played unstructured basketball at home. In this case, he played on his own when no one was available, and he was happy on his own at times.

Chase: I keep up with basketball and shoot [hoops] outside.

Interviewer: Do you do that with anybody?

Chase: Not exactly. I normally do that on my own. Sometimes people if they want to come over or not. Sometimes with my dad.

Interviewer: Do you prefer to play on your own or with somebody?

Chase: Somebody, but I'm fine either way. I like shooting on my own. I actually

like shooting and I don't need anyone there for that.

For Chase, socializing with peers in sport was nice but not always necessary or desired. He was happy to be solitary in his athletic pursuits when he was practicing his skills.

\section{Discussion}

Using a mixed methods approach, this exploratory study examined the social experiences of emerging adults with a disability in recreational sport programs and the applicability of observational methods for exploring social interactions within this population. Specifically, this study described the frequency, duration, and sequence of athletes' behaviours in such programs, and the individual experiences of navigating the disability sport world. Observed athletes with a disability were most often engaged with their recreational sport program's activities (based on frequency and duration noted in Tables 2 and 3) and communicated most often with a coach initiating the interaction. Teammates communicated with the athletes, albeit minimally, and in either general communication (e.g., speaking about weekend activities) or modeling sport skills. Discussions with the athletes indicated that parents and coaches were perceived by the athletes to actively support their recreational sport experiences. Additionally, the observational technique used in this mixed methods study, while challenging, was novel and, with the supplementary use of qualitative methods, provides a preliminary understanding of social influences within recreational sport programs involving emerging adult athletes with a disability. However, further testing of the modified observational coding system among athletes with a disability is warranted. The discussion will now turn to the implications for athletes, coaches, and researchers, followed by overall study strengths and directions for future research.

\section{Implications for Athletes}

The impact of peer interactions and dyadic peer relationships has been well documented (Shaw, Sweet, McBride, Adair, \& Martin Ginis, 2019; Solomon, 2004; Young et al., 2009) and the implications of peers on the quality of sport experiences has been theorised (Evans et al., 2018). However, in this study, athletes were not observed interacting with their teammates often and did not speak about peer relationships in sport, even when asked. Hence, the authors propose that direct peer interactions (e.g., conversations) may not naturally occur during sport program sessions; rather, the presence of peers alone may contribute to the sense of team, relationship, belonging, and may challenge the perception of disablism in sport settings for these athletes with predominantly impairments to social or cognitive skills (Richardson, Smith, \& Papathomas, 2017). In particular, the presence of individuals with similar abilities and impairments challenges the perception of disablism (Richardson et al., 2017). For example, teammates with similar abilities were present and available to connect with if desired, but constant interaction was not common. Moreover, the presence of peers with a disability, especially with similar impairments, may contribute to a positive social environment where their bodies are accepted (Richardson et al., 2017). Finally, the important roles that parents and coaches had on the athletes' experiences may 
influence the frequency and nature of teammate relationships within recreational sport programs, but more research is warranted to discern the impact supervised interactions have on peer relationships.

Notably, individuals with a disability have been documented as having fewer and lower quality friendships than their age-matched peers (Gorter et al., 2014). In this study, six of the eight athletes identified with impairments in social skills or cognition or both. These impairments can include nonverbal communication, withdrawal, sensory sensitivity (e.g., loud noises), and stereotypy behaviours (e.g., pacing; American Psychiatric Association, 2013). In a society that is not wholly accessible and often dominated by ableism, such behaviours and characteristics can be perceived as unusual, avoided, and also undesired (Nario-Redmond, 2019). Thus, individuals with impairments in social skills or cognition or both are often socially isolated with limited opportunity to build their social skills. However, recreational sport can be a way of addressing social skills (Haegele, 2018; e.g., Orr, Wright, Grassmann, McPherson, Faulkner \& Arbour-Nicitopoulos, 2019) such as through encouraging communication and modeling of appropriate social interactions by coaches and peers. Social interactions in sport are learning opportunities, where coaches and teammates can reinforce positive social interactions with the aim of transferring skills outside of sport, where they may be absent in other community settings.

Coaches were the primary individuals interacting with the athletes ( $87 \%$ of coded communication behaviours) and parents (or siblings in Hadi's experience) were heavily involved in their adult children's sport participation (as described by the athletes). These study findings were unexpected, as previous papers indicated the potential for sport to challenge avoidance and social isolation (e.g., Orr, Evans, et al. 2019). However, not all individuals - regardless of disability status - socialize in the same way. Therefore, the way individuals with impairments in social skills or cognition or both interact may look different to those without impairments, to meet their social needs. One point to note is that the athletes in the current study were registered in their sport programs for multiple seasons and the softball athletes had been teammates for several years. These athletes may have developed a way of interacting that avoided negative behaviours and maintained neutral and positive behaviours. For this reason, qualitative research, such as the interviews in this study, is vital for understanding athletes' needs, desires, and motivations. In future studies, multiple interviews that make use of the video footage may be useful in examining whether there is a more active role that peers can play in the transition to and experience of adult recreational sports for emerging adults with a disability must be explored further.

Finally, none of the negative behaviours (e.g., physical) were observed in this study. Although not observed, the authors recommend retaining these behaviours in the coding system for future studies. Being observed could mean that the athletes and their peers did not want to be recorded acting contrary to socially normative expectations. Moreover, this null finding could be interpreted as positive as it suggests that coaches were managing their teams in such a way that no observable negative interactions occurred. Contrastingly, the social exclusion that Suzie and Lizzie described in a previous softball program indicates that even 'acute' negative peer interactions can have lasting implications.

\section{Implications for Coaches}

While coaches were observed interacting with the athletes and identifying when athletes lost focus on the activities, there was minimal athlete-athlete interaction. Although not observed or discussed by the athletes in this study, peer mentorship is an important program element for adults with a disability (Shaw et al., 2019). Therefore, coaches may be interested in deliberately structuring peer relationships and mentorship roles to strengthen the peer environment. For emerging adults with a disability, the transition into adult programs and 
services may be daunting, but the experiences of peers may assist in navigating this new landscape (Shaw et al., 2019). Peers can be a source of motivation, evaluative communication, and a member of one's social network (Keegan et al., 2010), while contributing to decreased depressive symptoms and an enhanced sense of self and selfperceptions (Schwartz \& Sendor, 1999). Peers also contribute to the social environment that provides a (potentially) positive foundation for fostering quality (para)sport experiences (Evans et al., 2018). Quality sport experiences are posited to consist of a sense of belonging and meaning in one's role in the specified context (e.g., sport team; Evans et al., 2018), both of which peers may positively influence (Keegan et al., 2010; Schwartz \& Sendor, 1999). As Evans and colleagues (2018) discuss, extended exposure to quality peer experiences may influence maintained participation in the activity (in this case the recreational sport program) and have positive short- and long-term well-being outcomes.

Moreover, coaches may assist in the development of social skills by encouraging positive peer interactions and partner activities. However, this assumes that all coaches have the skills and confidence to conduct such activities which is not necessarily the case (Lepage, Bloom, \& Falcão 2020; MacDonald, Côté, \& Deakin 2010; Mallett et al. 2009) nor is there an abundance of coaches with a disability (Richardson et al., 2017). Based on the qualitative data, athletes spoke of how they did enjoy having peer athletes around whom they could talk to and play with at their sport programs (i.e., Suzie, Lizzie, Jon, Ron, Kevin, and Hadi). Nevertheless, peer athletes were not observed in the videos interacting frequently or in meaningful ways to suggest that communication or social skills or both were being deliberately planned by the coach (e.g., encouraging teamwork, partner activities). Additionally, there are concerns of how, once individuals with a disability age out of youth and school sports, they are often left to navigate adult programming on their own. Some individuals do this successfully yet, for athletes like Hadi, they are often left without anywhere to go (Gorter et al., 2014; Orr, Evans et al., 2019). Therefore, coaches and teachers in youth community and school sport programs must consider their role in fostering a smooth transition for their athletes with a disability (and arguably those without disability) who wish to continue to adult sport.

Lastly, the physical environment should be taken into consideration as it is part of the foundation of what makes a quality sport experience (Evans et al., 2018). While only a brief distraction (in observed duration) for Chase (basketball), the presence of his parents on the sidelines could potentially be a distraction. For Chase, the distraction was minimal, and he re-engaged in the program independently, but it was still a distraction enabled by the physical environment that should be considered when building, renovating, and arranging facilities for sports with athletes with impairments in social or cognitive skills or both.

\section{Practical Considerations for Observational Research}

First, the setup of the field equipment for the video observation was pragmatic for the safety and continuity of the programs. Working in locations where researchers are unfamiliar with the facility presents challenges for videotaping. For example, at the softball program, the interviewer was inhibited by a forest surrounding most of the diamond's perimeter. Second, recruitment of athletes and programs that are open to video observation can be difficult. However, identification of a key stakeholder (e., parent) can expedite recruitment (e.g., one scheduled softball athlete turned into five). Third, the observational methodology is highly recommended for further use in recreational sports for individuals with and without disabilities across the lifespan. As this and previous studies (Erickson et al., 2011; Turnnidge, Côté, Hollenstein, \& Deakin, 2014) have shown, detailed coding of video observations can provide insights into the communication strategies of peers and coaches, and has the potential to link them with outcomes of interest. Fourth, the mixed 
methods approach was beneficial for understanding the complexity of social influences given the lack of observed athlete-athlete interactions in the observation data. These interactions may be typical or altered given the camera and researcher present (white coat effect; e.g., Geh et al., 2011). Future research should consider similar approaches to provide a comprehensive understanding of the social environment in sport and other settings. Fifth, working with athletes with impairments in social or cognitive skills or both allows the opportunity to be creative and amenable to multiple ways of expressing oneself. Thus, the methods that researchers and practitioners use must reflect that way of being. Observational methods, such as those implemented in this study, can provide insight and offer the opportunities for individuals with alternative communication styles to be involved in research.

\section{Strengths and Limitations}

This study had a small yet, varied sample of emerging adults with a disability in recreational sports programs. Larger studies are warranted and the modified observational code was shown to be acceptable for use in these settings and within the sample. Additionally, the athletes were primarily males (five of eight), which is typical of emerging adults in sport with and without disabilities (Darcy \& Dowse, 2013; Memari et al., 2013). With more female athletes, communication may be observed differently. Having additional researchers onsite to collect data may aid in the clarity of the observable video which will enhance the coding and data analysis processes. Moreover, the addition of a group interview rather than one-on-one interviews may have inhibited some discussions from occurring based on comfort and communication abilities of the athletes (Stewart \& Shamdasani 2014). The addition of a group interview is consistent with the flexible nature of qualitative inquiry that allows for emergent design to capitalize on opportunities in the field. The group interview in this study provided an opportunity to adopt our approach and provide a welcoming research experience for the participants. Despite these limitations, this study is the first to explore the potential for observational techniques to capture the social interactions of emerging adult athletes with disabilities in recreational sport programs. Thus, this study provides a preliminary examination of the interpersonal interactions between teammates with coaches and demonstrates the utility of using observational coding for the examination of social interactions of athletes with a disability in recreational sport programs.

\section{Conclusions}

This study used an exploratory mixed methods design to describe and evaluate the social interactions between teammates and coaches, as well as experiences in recreational sport programs for emerging adults with a disability. Findings suggest that peers have a passive yet important role in providing a space for individual athletes with a disability to feel welcome and can achieve their sport-related goals. In the observed sport programs, peers were present in the same programs and not encouraged to interact by coaches. Thus, coaches are encouraged to not only work on sport-related skills, but the social skills of their athletes with a disability. Furthermore, the observational coding technique utilized to examine the social interactions in this study is applicable to athlete-athlete interactions among emerging adults with a disability.

\section{Perspectives}

The findings of this study highlight the usefulness of a mixed methods approach to understanding the complexity of social experiences within recreational sports for emerging adults with a disability. Parents and coaches have a continued influential role to play for emerging adults with a disability in recreational sports that may not occur among emerging 
adults without disabilities (e.g., Arnett, 2000; Gorter et al., 2014). Thus, peers play an important yet passive role in establishing a positive, welcoming environment for emerging adult athletes with a disability. The observed sport programs were designed for athletes with a disability and provided small group or one-on-one support as required. Therefore, sport programs with limited support should be observed and explore the peer interactions therein.

\section{Author affiliations:}

1 Faculty of Kinesiology and Physical Education, Mental Health and Physical Activity Research Centre, University of Toronto, Toronto, Canada; krystn.orr@mail.utoronto.ca

2 Faculty of Kinesiology and Physical Education, University of Toronto, Toronto, Canada; katherine.tamminen@utoronto.ca

3 Department of Kinesiology, Pennsylvania State University, University Park, USA; mbe13@psu.edu

4 Faculty of Kinesiology and Physical Education, Mental Health and Physical Activity Research Centre, University of Toronto, Toronto, Canada; Bloorview Research Institute, Toronto, Canada; kelly.arbour@utoronto.ca

*Corresponding author: Krystn Orr: krystn.orr@mail.utoronto.ca

Author Contributions: Conceptualization: KO, KAT, MBE, KAN; Methodology: KO, KAT, MBE, KAN; Formal Analysis: KO; Writing Original Draft Preparation: KO; Writing, Review, \& Editing: KO, KAT, MBE, KAN.

Funding: This research received funding from the Social Sciences and Humanities Research Council of Canada, Doctoral Fellowship awarded to Krystn Orr, grant \#767-2018-2533.

Acknowledgments: The authors would like to acknowledge the support of Special Olympics Ontario in the conduct of this study.

Conflicts of Interest: The authors declare no conflict of interest.

\section{References}

Allan, V., Turnnidge, J., Vierimaa, M., Davis, P., \& Côté, J. (2016). Development of the assessment of coach emotions systematic observation instrument: A tool to evaluate coaches' emotions in the youth sport context. International Journal of Sports Science and Coaching, 11(6), 859-871. https://doi.org/10.1177/1747954116676113

American Psychiatric Association. (2013). Diagnostic and statistical manual of mental disorders (DSM-5®), Fifth Edition (5th ed.).

https://www.psychiatry.org/psychiatrists/practice/dsm

Arnett, J. J. (2000). Emerging adulthood: A theory of development from the late teens through the twenties. American Psychologist, 55(5), 469-480.

https://doi.org/10.1037/0003-066X.55.5.469

Bekker, S., Bolling, C., H Ahmed, O., Badenhorst, M., Carmichael, J., Fagher, K.,... Verhagen, E. A. (2020). Athlete health protection: Why qualitative research matters. Journal of Science and Medicine in Sport, 23(10), 898-901. https://doi.org/10.1016/j.jsams.2020.06.020

Braun, V., \& Clarke, V. (2019). Reflecting on reflexive thematic analysis. Qualitative Research in Sport, Exercise and Health, 11(4), 589-597. https://doi.org/10.1080/2159676X.2019.1628806

Braun, V., Clarke, V., \& Weate, P. (2016). Using thematic analysis in sport and exercise research. Routledge Handbooks Online. https://doi.org/10.4324/9781315762012.ch15

Charalampos, S., Silva, C. F., \& Kudlacek, M. (2015). When sitting becomes sport: Life stories in sitting volleyball. European Journal of Adapted Physical Activity 8(1), 3044. https://doi.org/10.5507/euj.2015.003.

Chemtob, K., Caron, J. G., Fortier, M. S., Latimer-Cheung, A. E., Zelaya, W., \& Sweet, S. N. (2018). Exploring the peer mentorship experiences of adults with spinal cord injury. Rehabilitation Psychology, 63(4), 542-552. https://doi.org/10.1037/repo000228

Cobley, P. (2008). Communication: Definitions and Concepts. In W. Donsbach (Ed.) The International Encyclopedia of Communication (pp. 1-7). https://doi.org/10.1002/9781405186407.wbiecc071

Creswell, J. W., \& Plano Clark, V. L. (Eds.). (2020). Designing and conducting mixed methods research. Retrieved from: https://us.Sagepub.com/en-us/nam/designingand-conducting-mixed-methods-research/book241842 
Darcy, S., \& Dowse, L. (2013). In search of a level playing field - the constraints and benefits of sport participation for people with intellectual disability. Disability \& Society, 28(3), 393-407. https://doi.org/10.1080/09687599.2012.714258

Douglas, S., Falcão, W. R., \& Bloom, G. A. (2018). Career development and learning pathways of Paralympic coaches with a disability. Adapted Physical Activity Quarterly, 35(1), 93-110. https://doi.org/10.1123/apaq.2017-0010

Erickson, K., Côté, J., Hollenstein, T., \& Deakin, J. (2011). Examining coach-athlete interactions using state space grids: An observation analysis in competitive youth sport. Psychology of Sport and Exercise, 12, 645-654. https://doi.org/10.1016/j.psychsport.2011.06.006

Erickson, K., Wright, E., Kochanek, J., \& Vierimaa, M. (2020). Chapter 13-Peer influence and youth development. In M. W. Bruner, M. A. Eys, \& L. J. Martin (Eds.), The Power of Groups in Youth Sport (pp. 221-240). Cambridge, MA: Academic Press. https://doi.org/10.1016/B978-0-12-816336-8.00013-5

Evans, M. B., Eys, M. A., \& Bruner, M. W. (2012). Seeing the "we" in "me" sports: The need to consider individual sport team environments. Canadian Psychology/Psychologie Canadienne, 53(4), 301-308. https://doi.org/10.1037/a0030202

Evans, M. B., Shirazipour, C. H., Allan, V., Zanhour, M., Sweet, S. N., Martin Ginis, K. A., \& Latimer-Cheung, A. E. (2018). Integrating insights from the parasport community to understand optimal Experiences: The Quality Parasport Participation Framework. Psychology of Sport and Exercise, 37, 79-90. https://doi.org/10.1016/j.psychsport.2018.04.009

Eys, M., Bruner, M. W., \& Martin, L. J. (2019). The dynamic group environment in sport and exercise. Psychology of Sport and Exercise, 42, 40-47. https://doi.org/10.1016/j.psychsport.2018.11.001

Gardner, H., \& Randall, D. (2012). The effects of the presence or absence of parents on interviews with children. Nurse Researcher, 19(2), 6-10. https://doi.org/10.7748/nr2012.01.19.2.6.c8902

Geh, C. L., Beauchamp, M. R., Crocker, P. R., \& Carpenter, M. G. (2011). Assessed and distressed: White-coat effects on clinical balance performance. Journal of Psychosomatic Research, 7o(1), 45-51.

Gorter, J. W., Stewart, D., Smith, M. W., King, G., Wright, M., Nguyen, T., Freeman, M., \& Swinton, M. (2014). Pathways toward positive psychosocial outcomes and mental health for youth with disabilities: A knowledge synthesis of developmental trajectories. Canadian Journal of Community Mental Health, 33(1), 45-61. https://doi.org/10.7870/cjemh-2014-005

Haegele, J. (2018). Youth leisure-time physical activity from the perspectives of young adults with visual impairments. European Journal of Adapted Physical Activity 11(2), 1-13. https://doi.org/10.5507/euj.2018.010

Keegan, R., Spray, C., Harwood, C., \& Lavallee, D. (2010). The motivational atmosphere in youth sport: Coach, parent, and peer influences on motivation in specializing sport participants. Journal of Applied Sport Psychology, 22(1), 87-105. https://doi.org/10.1080/10413200903421267

Lepage, P., Bloom, G. A., \& Falcão, W. R. (2020). Development and acquisition of knowledge of youth parasport coaches. Adapted Physical Activity Quarterly, 37(1), 72-89. https://doi.org/10.1123/apaq.2019-0017

Lewis, M. D., Lamey, A. V., \& Douglas, L. (1999). A new dynamic systems method for the analysis of early socioemotional development. Developmental Science, 2(4), 457-475. https://doi.org/10.1111/1467-7687.00090

Lincoln, Y. S., \& Guba, E. G. (1985). Naturalistic inquiry. Thousand Oaks, CA: Sage Publications, Inc.

Lincoln, Y. S., Lynham, S. A., \& Guba, E. G. (2011). Paradignmatic controversies, contradictions, and emerging confluences, revisited. In N. K. Denzin \& Y. S. Lincoln (Eds.), The SAGE Handbook of Qualitative Research (Vol. 4, p. 34) Thousand Oaks, CA: Sage Publications, Inc. 
Loughead, T. M., \& Hardy, J. (2005). An examination of coach and peer leader behaviors in sport. Psychology of Sport and Exercise, 6(3), 303-312.

https://doi.org/10.1016/j.psychsport.2004.02.001

MacDonald, D. J., Côté, J., \& Deakin, J. (2010). The impact of informal coach training on the personal development of youth sport athletes. International Journal of Sports Science \& Coaching, 5(3), 363-372. https://doi.org/10.1260/1747-9541.5.3.363

Mallett, C. J., Trudel, P., Lyle, J., \& Rynne, S. B. (2009). Formal vs. Informal coach education. International Journal of Sports Science \& Coaching, 4(3), 325-364. https://doi.org/10.1260/174795409789623883

Marton, K. (2009). Imitation of body postures and hand movements in children with specific language impairment. Journal of Experimental Child Psychology, 102(1), 113. https://doi.org/10.1016/j.jecp.2008.07.007

McKim, C. A. (2017). The value of mixed methods research: A mixed methods study. Journal of Mixed Methods Research, 11(2), 202-222. https://doi.org/10.1177/1558689815607096

Memari, A. H., Ghaheri, B., Ziaee, V., Kordi, R., Hafizi, S., \& Moshayedi, P. (2013). Physical activity in children and adolescents with autism assessed by triaxial accelerometry. Pediatric Obesity, 8(2), 150-158. https://doi.org/10.1111/j.2047-6310.2012.00101.X

Mertens, D. M., \& Hesse-Biber, S. (2012). Triangulation and mixed methods research: Provocative positions. Journal of Mixed Methods Research, 6(2), 75-79. https://doi.org/10.1177/1558689812437100

Murphy-Mills, J., Bruner, M. W., Erickson, K., \& Côté, J. (2011). The utility of the state space grid method for studying peer interactions in youth sport. Journal of Applied Sport Psychology, 23(2), 159-174. https://doi.org/10.1080/10413200.2010.545101

Nario-Redmond, M. R. (2019). Ableism: The causes and consequences of disability prejudice. Toronto, ON: Wiley-Blackwell. https://www.wiley.com/enus/Ableism\%3A+The+Causes+and+Consequences+of+Disability+Prejudice-p9781119142072

O'Cathain, A. (2010). Assessing the quality of mixed methods research: Toward a comprehensive framework. In A. Tashakkori \& C. Teddlie, Sage Handbook of Mixed Methods in Social \& Behavioral Research (pp. 531-556). Thousand Oaks, CA: Sage Publications, Inc. https://doi.org/10.4135/9781506335193.n21

Oja, P., Titze, S., Kokko, S., Kujala, U. M., Heinonen, A., Kelly, P., Koski, P., \& Foster, C. (2015). Health benefits of different sport disciplines for adults: Systematic review of observational and intervention studies with meta-analysis. British Journal of Sports Medicine, 49(7), 434-440. https://doi.org/10.1136/bjsports-2014-093885

Orr, K., Evans, M. B., Tamminen, K. A., \& Arbour-Nicitopoulos, K. P. (2019). A scoping review of recreational sport programs for disabled emerging adults. Research Quarterly for Exercise and Sport, 91(1), 142-157. https://doi.org/10.1080/02701367.2019.1653432

Orr, K., Tamminen, K. A., Sweet, S. N., Tomasone, J. R., \& Arbour-Nicitopoulos, K. P. (2018). "I've had bad experiences with team sport": Sport participation, peer needthwarting, and need-supporting behaviors among youth identifying with physical disability. Adapted Physical Activity Quarterly, 35(1), 36-56. https://doi.org/10.1123/apaq.2017-0028

Orr, K., Wright, F. V., Grassmann, V., McPherson, A. C., Faulkner, G. E., \& ArbourNicitopoulos, K. P. (2019). Children and youth with impairments in social skills and cognition in out-of-school time inclusive physical activity programs: A scoping review. International Journal of Developmental Disabilities, 65, 1-15. https://doi.org/10.1080/20473869.2019.1603731

Pinquart, M., \& Pfeiffer, J. P. (2015a). Solving developmental tasks in adolescents with a chronic physical illness or physical/sensory disability: A meta-analysis. International Journal of Disability, Development and Education, 62(3), 249-264. https://doi.org/10.1080/1034912X.2015.1020922

Pinquart, M., \& Pfeiffer, J. P. (2015b). Bullying in students with and without hearing loss. Deafness \& Education International, 17(2), 101-110. https://doi.org/10.1179/1557069X14Y.0000000044 
Renwick, R., DuBois, D., Cowen, J., Cameron, D., Fudge Schormans, A., \& Rose, N. (2019). Voices of youths on engagement in community life: A theoretical framework of belonging. Disability \& Society, 34(6), 945-971. https://doi.org/10.1080/09687599.2019.1583551

Richardson, E. V., Smith, B., \& Papathomas, A. (2017). Disability and the gym: Experiences, barriers, and facilitators of gym use for individuals with physical disabilities. Disability and Rehabilitation, 39(19), 1950-1957. https://doi.org/10.1080/09638288.2016.1213893

Rubin, K. H., Bukowski, W. M., \& Parker, J. G. (2007). Peer interactions, relationships, and groups. In W. Damon \& R. M. Lerner (Eds.), Handbook of Child Psychology (pp. 3). Hoboken, NJ, USA: John Wiley \& Sons, Inc. https://doi.org/10.1002/9780470147658.chpsy0310

Schwartz, C. E., \& Sendor, R. M. (1999). Helping others helps oneself: Response shift effects in peer support. Social Science \& Medicine, 48(11), 1563-1575. https://doi.org/10.1016/So277-9536(99)00049-0

Shaw, R. B., Sweet, S. N., McBride, C. B., Adair, W. K., \& Martin Ginis, K. A. (2019). Operationalizing the reach, effectiveness, adoption, implementation, maintenance (RE-AIM) framework to evaluate the collective impact of autonomous community programs that promote health and well-being. BMC Public Health, 19(1), 803. https://doi.org/10.1186/s12889-019-7131-4

Smith, B., Sparkes, A. C., Phoenix, C., \& Kirkby, J. (2012). Qualitative research in physical therapy: A critical discussion on mixed-method research. Physical Therapy Reviews, 17(6), 374-381. https://doi.org/10.1179/1743288X12Y.0000000030

Solomon, P. (2004). Peer Support/Peer Provided Services Underlying Processes, Benefits, and Critical Ingredients. Psychiatric Rehabilitation Journal 27(4),392-401. https://doi.org/10.2975/27.2004.392.401

Turnnidge, J., Côté, J., \& Hancock, D. J. (2014). Positive youth development from sport to life: Explicit or implicit transfer? Quest, 66(2), 203-217. https://doi.org/10.1080/00336297.2013.867275

Turnnidge, J., Côté, J., Hollenstein, T., \& Deakin, J. (2014). A direct observation of the dynamic content and structure of coach-athlete interactions in a model sport program. Journal of Applied Sport Psychology, 26(2), 225-240. https://doi.org/10.1080/10413200.2013.821637

United Nations. (2006). Convention on the rights of persons with disabilities. https://www.un.org/development/desa/disabilities/convention-on-the-rights-ofpersons-with-disabilities.html

Vierimaa, M., \& Côté, J. (2016). An exploration of sociometric status and peer relations in youth sport. Journal of Sport Behavior, 39(1), 72-91.

Wu, S., \& Williams, T. (2001). Factors influencing sport participation among athletes with spinal cord injury. Medicine and Science in Sports and Exercise, 33(2), 177-182. https://doi.org/10.1097/00005768-200102000-00001

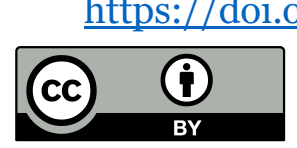

(C) 2021 by the authors. Submitted for possible open access publication under the terms and conditions of the Creative Commons Attribution (CC BY) license (http://creativecommons.org/licenses/by/4.o/). 